\title{
Book Review: What you really need to know about Counselling and Psychotherapy Training
}

\author{
Cathy McQuaid, London and New York: Routledge, 2014, 200 pages
}

\author{
Julie Hay
}

Subtitled as An Essential Guide, this book presents the results of Cathy McQuaid's doctoral research in a way that makes it useful to students considering their training options, in the expectation that this will result in "... The most rewarding and transformative experience they have ever encountered, and one that can be deeply reparative . . . [Rather than one that leaves them feeling] puzzled, confused, frustrated, and even betrayed, when they discover the reality of what they have taken on." (p.1)

During her research, McQuaid writes that she interviewed about 50, ranging from those who decided not to finish the training through to those who went on from their initial training to qualify as trainers themselves. She used Interpretative Phenomenological Analysis (IPA) (Smith, 1995) and identified five main themes and five main concerns.

As for a research paper, the first chapter provides the 'literature review' - in this case definitions of counselling and psychotherapy, theories of learning, and some useful tables detailing academic levels and qualifications, with the latter relating the UK \& Northern Ireland (UK/NI) to the European Qualifications Framework (EQF).

Chapter 2 continues the background review with a helpful summary of counselling and psychotherapy modalities. McQuaid sensibly limits the 400 or so differently named approaches in Karasu's (1986) survey to those accredited nowadays by the main professional bodies. She describes Art, Drama and Music therapies; Cognitive Analytic and Cognitive Behavioural; Existential and Personal Construct as subdivisions of Constructivist; Family, Couples and Systemic; Humanistic and Integrative which includes Gestalt; Person-Centred; Psychosynthesis and Transpersonal alongside Transactional Analysis; Hypno-psychotherapy; Psychoanalysis, including
Group Analysis and Jungian Analysis; and Sexual and Relationship.

The third chapter outlines entry requirements and course curricula because the lack of clarity about these was a key finding of McQuaid's research.

In Chapter 4, McQuaid describes the personal impact of training and the relevance of (and generally requirement of professional bodies) for personal therapy during training. Reflective practices are also described as a set of key skills. A checklist is provided with questions to ask a potential therapist.

The impact on self is continued in Chapter 5 , where McQuaid presents the six main themes of: relationship with the trainer; bonding between peers; the transformational impact of the training; the nature of the training group; the importance of ethics; and the sense of belonging during and after the training. Here McQuaid links her research findings to various theories, including phases of transformational learning (Mezirow, 1991), group stages (Tuckman, 1965), and attachment (Ainsworth \& Bell, 1970). I have my doubts about the wisdom of including the unconscious competence model (which McQuaid references to Robinson 1974 although this attribution has been challenged elsewhere) because I doubt that it is ever a 'good thing' for a therapist to relax into unconscious competence. I also thought that Berne's (1963) concept of group imagoes would have provided more reflective understanding of group processes, and would have made clearer the tendency to psychologically recreate our families of origin.

In Chapter 6, McQuaid comments that all of the interviewees said they reached a stage of disillusionment with their course, usually between the second and third years. In my view, being told this 
will be an effective normalisation for a student. McQuaid also provides information on the ways in which disillusionment may be prompted, such as expectations not being met, the challenge of academic work, the unexpectedly high level of personal change, the eventual realisation that it is not easy to find clients or jobs, coupled with the difficulties of achieving a satisfactory financial situation. Various suggestions are included to help deal with these themes.

Chapter 7 goes on to provide more specific ideas about employment opportunities and how the various qualification options affect job prospects. A 'political' view is presented about the implications of statutory and voluntary registration, and the availability of accreditation and registration systems run by various UK/NI associations and the European Association for Psychotherapy (EAP).

The final chapter presents a 12-step plan of action, referring back to the questions that McQuaid includes at the end of each of the previous chapters. This is supported by Appendices that list the main accreditation/regulatory bodies and other relevant professional organisations, provide examples of logbook templates and a personal learning contract, and a glossary of terms used in the book.

This highly practical book is an excellent example of the usefulness of research, as McQuaid presents the results of her IPA in ways that are easily comprehended by the reader. I suggest it will become 'required reading' for all potential counselling and psychotherapy students; even those outside the UK/NI will find much of interest. I look forward to the publication of McQuaid's research paper, hopefully in the next issue of IJTAR.

\section{References}

Ainsworth, M D S \& Bell, S M (1970) Attachment, exploration, and separation: illustrated by the behaviour of one-year-olds in a strange situation. Child Development, 41 49-67

Berne, E (1963) Structure and Dynamics of Organizations and Groups Philadelphia: Lippincott

Karasu, T B (1986) The specificity versus nonspecificity dilemma: toward identifying therapeutic change agents. American Journal of Psychiatry 143 687-695

Mezirow, J (1991) Transformative Dimensions in Adult Learning. San Francisco, CA; Jossey-Bass

Robinson, W L (1974) Conscious competency - the mark of a competent instructor. Personnel Journal, 53 538-539

Smith, J A (1995) Semi-structured interviewing and qualitative analysis. in Smith,J A, Harre, R \&Van Langenhouve, L (eds) (1995) Rethinking Methods in Psychology. London: Sage

Tuckman, B (1965) Developmental sequence in small groups. Psychological Bulletin 63 (6) 384-399 